\title{
Development the tool for demand control ventilation systems elements design and their impact to building life-cycle assessment: a review
}

\author{
Richard Pinka, ${ }^{1, *}$ \\ ${ }^{1}$ CTU in Prague -Faculty of Civil Engineering, Department of Applied Informatics, Thákurova 7 \\ 166 29, Prague, Czech Republic
}

\begin{abstract}
The paper describes possible methodology for DCV - demand control ventilation design process which will lead to solving the most important problems of more accurate ventilation system design, the efficiency: time and costs of design while improving its effectivity (level of design confidence, degree of uncertainty, financial parameters). For this purpose it has been started developing the tool implementing the methodology. Furthermore, it describes steps of testing and validation design process by implementation state-of-the-art algorithms for measuring the occupancy or CO2 detection for DCV system control testing sites and their comparison with computation design results. It describes also the reasons and necessity of decomposition of whole ventilation system to specific elements for the design and assessment procedure.
\end{abstract}

\section{Introduction}

In modern commercial and office buildings over Europe is actual trend to design more interconnected HVAC systems together. As stated in [1], systems of ventilation and climatization has a frontier position within the buildings energy consumption based on the either consumption of the cooling/heating energy (as well as energy for humidification or dehumidification for climatization systems) for maintaining the air temperature and consumption for fans operation. HVAC systems conceptually divided far apart do not use the advantages of each other for the energy efficient operation, which often leads to different concept misconduct issues. The need of energy consumption reduction tends to integrate more HVAC systems together, fancoil units for the cooling purposes are smoothly changing for induction units i.e. cooling beams, connecting the cooling system with the ventilation system. The intake air for cooling beams increase their cooling capacity based on the income cooling water and if this concept is used for building as a whole, it gives better energy performance of the cooling source, because of lowering the cooling water temperature difference used to cool the air above dew point temperature (e.g. EWT/LWT

\footnotetext{
${ }^{*}$ Corresponding author: richard.pinka@,fsv.cvut.cz
} 
$18 / 21{ }^{\circ} \mathrm{C}$ instead of $6 / 12^{\circ} \mathrm{C}$ ) as of the case of cooling fan-coils design. Nevertheless, going to the side of the air and ventilation system, more sophisticated design brings more questions such:

- Shall be prioritized air temperature and airflow or water flow for cooling capacity regulation of the induction units for interior temperature regulation?

- Shall prevail regulation dampers based on the CAV or VAV concept?

- Similarly, shall be preferred constant water flow or variable water flow system?

- How many dampers and which position shall be defined for the best price/performance ratio? Which type of actuators shall dampers have?

- Will the system be enough flexible for future interior changes?

- Last, but not least - is the DCV design expendable or favourable for the specific project circumstances?

Each question is related to each other and together they are defining the dimensions/options of system design and assessment. First dimension is duct system. Low operating energy consumption may be reached by choosing a low duct system friction $\Delta p$ by appropriate duct system design. Pressure drop is often increased by inappropriate concept of duct system due to limited space and shafts for ducts, causing high width/height duct ratio, small flow area and higher amount of duct elbows. Another dimension of the design leading to energy costs reduction is to minimize the operating demand of an air flow volume $\mathrm{V}$ over the operating time and appropriate design of the regulation elements and their control for air distribution: these aspects of design are the main topic of this paper.

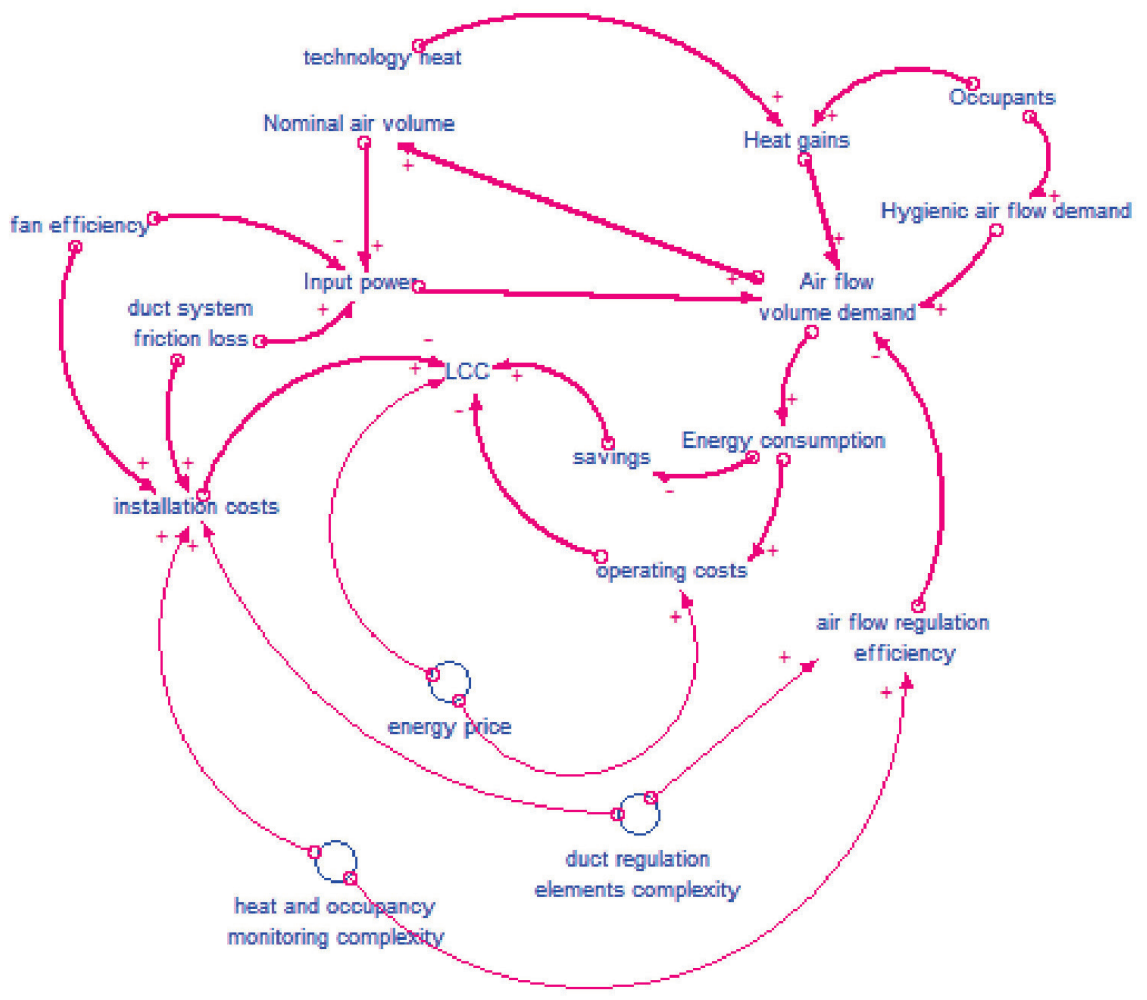

Fig. 1. Influences and relationships in the ventilation system design. 
As is seen on Fig.1, the relations of the design dimensions define whether there is positive or negative impact within their relations. Installation costs, savings, operation costs may be the most important evaluation criteria for investor but may be considered by each investor differently, based on his experience and priorities. Relationships between these specific physical and intangible phenomena influencing ventilation system design is difficult to determine with high accuracy without proper tools. Nevertheless, due to the informational technologies development, such tools development is in today focus. Important aspect for the evaluation are quality of hardware installed: duct system defining the friction loss, and quality of technology: fan efficiencies. Very important role for operation air flow volume demand has the system's ability to distribute the air right to the zones where it is needed and no more anywhere else. This ability named in Fig. 1 as a duct regulation elements complexity may offer high flexibility to the system in the matter of air distribution minimization. Distribution logic is described furthermore in part about the distribution and control strategies and in Fig.4. Different but essential design dimension is about data inputs for the BAS control system, to find strategy how to send right inputs about the IAQ to the system. All of these aspects are considered design stage sensitively to higher installation costs price - which are missing important data about life-cycle system costs very often due the lack of designing tools able to absorb and process data. These design options thus fall to the disgrace very often. With investor's aim to save investment money, not the operation money, may the reduction costs on regulation elements bring more issues in future than wished. Such most occurring issues not influencing only energy consumption may be:

- wrong basic concept - interfering by long-term facts not taking into account;

- overestimating the volume of cooling source's cooling capacity;

- overloaded ventilation flow over the operating time based on the lack of conceptual regulation elements in ducting system - relatively higher energy consumption;

- insufficient ventilation capacity of AHU based on lack of regulation elements;

- wrong control design and logic - missing the proper monitoring tools or proper metric algorithms for the system control;

- unable to set up or tune up the system after some period of operation or after the interior conceptual changes.

\section{Methodology definition on a case study building}

The matter of the research is to firstly create the tool for base computation models used for design air distribution within building zones and its energy consumption estimation. This tool will be able to import parametric data from selected open BIM filetypes- i.e. IFC filetype. Models will further implement different control strategies based on selected system regulation element types (actuator types or whole types, e.g. in Fig.7). The matter of research moreover will include definition of the control input data strategies. The variants of strategies based on the computation model will be able to compare between each other and in the later stage will be an effort to compare computation results with measurements on appropriate model-like sites for the tool validation.

The first computational model design is developed on the data based on newly built office building with 7 storeys situated in the Prague. The computation model is based on ventilation system for the ventilation of $2^{\text {nd }}$ to $7^{\text {th }}$ floor. The system consists of two AHU units situated on roof. Due to similar space layouts the model was simplified by used of one $2^{\text {nd }}$ storey ( 40 zones), two $3^{\text {rd }}$ storeys $\left(2 \times 51\right.$ zones) and three $4^{\text {th }}(3 \times 52$ zones $)$ storeys for reaching the number of 7 storeys. Complex computational model includes 298 zones in total. 
Primarily, an "air flow demand" will be defined by a concrete design elementary input data-sets such as occupancy numbers/rates, solar/lighting/body/notebook heat gains in each zone specified each dayhour. Based on air distribution and control strategies, the "air supply", which energy consumption will be estimated on, will be defined afterwards. Air demand and supply will take into account the occupancy ratio by occupancy curves and occupancy probabilities as another design dimensions and input variables to the model. The model will then modify regulation characteristics per each room separately, according distribution elements (cooling beams) and its regulation/control possibilities in each zone. Axioms, which are considered for this topic are:

- volumes of air flows defined within ventilation system designs are mostly CAV and are hard to set;

- ventilation system is considered with equilateral pressures both on Supply and Outlet sides. Supply and Outlet air flows will be thus equal as well.

\subsection{Practical aspects of computational model design}

Various cooling/ventilation demands depends on the interior zone type (e.g. meeting rooms, open-offices, offices, kitchen, quiet rooms, corridors etc.) and their people/technology maximum loads, which has been further multiplied by the coefficients according the occupancy schedule and presence probabilities in smaller rooms (set to 0,625), because to have always $100 \%$ of maximum designed values is not proper operation profile.

Cooling load is variable input for design based on a) a zone position at the floor layout (e.g. near façade, on corner, without façade/window connection), b) daytime and month, c) actual zone occupancy- heat gains by human bodies and PC usage ([nominal value] $\mathrm{x}$ [multiplier according occupancy curves]), d) lighting heat gains if appropriate time. Air flows demands of all zones sums the total operation air volume demand. From this demand, the pressure drop is specified. Friction drop of system consists of duct system friction curve, (duct system friction is function of air flow). For the estimation of electric power necessary to transport the required air flow, additional pressure drops of AHU unit (531 $\mathrm{Pa}$ of internal pressure) and $20 \mathrm{~Pa}$ as of cooling beams pressure drop were included to the total operating pressure drop. Possible pressure drops of evaluated duct dampers were neglected.

Two logic setpoints for air flow regulation are defined - $\mathrm{CO} 2$ regulation and temperature regulation. As stated in formula (1), total air flow volume for cooling is defined:

$$
\begin{aligned}
& \text { [Solar h.gains] }(W)+[\text { Lighting h.gains }](W)+[\text { Persons }+ \text { laptops }](W)=Q_{\text {cool,demand,time,zone }} \\
& \text { [Lighting h.gains] }(W)=Q_{\text {light,max }} \text { zone }(W) \text {. coef light,time }(\%) \\
& {\left[\text { Persons }+ \text { laptops] }(W)=\text { Persons, } \text { max,zone (-) . coef,occupants, } P(\%) \cdot\left[Q_{p e r s o n, z}+Q_{p c, z}\right](W)\right.}
\end{aligned}
$$

By the logic of long-term energy estimation, sum of heat gains consists of solar heat gains in specific dayhour/month for solar gains. Heat gains data means array of at least $8 \mathrm{x}$ 12 data cell structure matrix (maximum 24 x 12) per each computational part (each zone). The sum of total operating air volume demand defines its pressure loss by interpolating data within prepared pressure drop curve. 


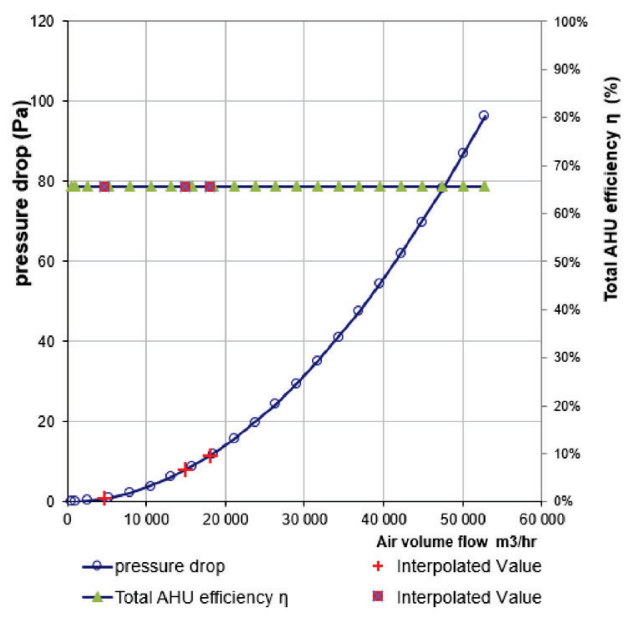

Fig. 2. Duct system friction loss curve according computed values. Interpolated values shown in figure shows example of values interpolated for the computational model operation point. Total AHU efficiency is considered for whole operating profile as a constant.

Required air volume for supply demand for cooling according defined occupancy based on operation profiles is then computed as:

[Persons,max (-). Air volume per person $\left(m^{3} /\right.$ hour.person $\left.)\right]$. coef,occup,P(\%) $=V_{\text {hyg,demand,zone }}\left(\mathrm{m}^{3} /\right.$ hour $)$

Specific situation with small privacy and phone rooms where random factor of occupancy is needed, hygienic volume and cooling heat gains has been determined as:

$$
\begin{gathered}
{[\text { Persons,max (-) . Probability }(0,625)] .100(\%)=V_{\text {hyg,demand,zone }}\left(\mathrm{m}^{3} / \text { hour }\right)} \\
[\text { Persons,max (-) . Probability }(0,625)] .100(\%) \text {. [Persons }+ \text { laptops }](\mathrm{W})=Q_{\text {cool,demand,time,zone }}(\mathrm{W})
\end{gathered}
$$

When heat loads for cooling were determined, appropriate volume of demanded air flow volume is known by the fact, cooling capacity of each induction unit is conditioned by specific air flow. In design were defined three types of cooling induction units, with the names CB1, CB2, CB3, with nominal designed cooling capacities 1255, 928, $503 \mathrm{~W}$ and with specific nominal design air flows $155,120,80 \mathrm{~m} 3 /$ hour. These induction units may be regulated differently according selected actuators for regulation dampers (if installed), according Fig.3. Each of 298 zones has either its own set of cooling beams or hasn't none and thus is not considered in model. Air flow demand for actual operation is thus a ratio of actual heat gain and maximum cooling capacity in zone multiplied by nominal air flow for cooling in zone as seen in formula:

$$
Q_{\text {cool,demand,time,zone }}(W) / Q_{\text {cool,design,nom,zone }}(W) \text {. } V_{\text {cool,max,zone }}\left(\mathrm{m}^{3} / \text { hour }\right)=V_{\text {cool,demand,zone }}\left(\mathrm{m}^{3} / \text { hour }\right)
$$

A required operating ventilation needs for further computation are higher values from $V_{\text {hyg,demand,zone }}$ or $V_{\text {cool,demand,zone named as }} V_{\text {demand,zone,time. }}$. When demand side of evaluation process is finished, supply side shall define how to supply the air more efficiently. As was already mentioned, there is more options to let the air distribute. That is the reason, why the final air flow demand will not be the same as air flow supply, finally implemented in 
operation (computational model simulation). No matter the fact, supply side will result in many different results based on the system controller types and their locations, the electricity consumption needed for air transport based on specified concepts, will be defined by firstly estimation the required mechanical power, $\mathrm{P}_{\text {mech }}$, necessary to pass the required volume flow through duct system by defined pressure drop function as in :

$$
P, \text { mech }=V . \Delta p \quad \text { where } \quad \Delta p=f(V)
$$

To estimate electric input power for the mechanical movement of fans, there shall be included total AHU efficiency:

$$
P, e l=V . \Delta p / \eta_{t o t, A H U}
$$

Where $\mathrm{V}$ is nominal air flow volume $(\mathrm{m} 3 / \mathrm{h} ; \mathrm{m} 3 / \mathrm{s} ; \mathrm{cfm}), \Delta \mathrm{p}$ is specific nominal pressure drop (friction drop or head loss plus internal pressure drop of AHU and induction units) of the system $(\mathrm{Pa})$ and $\eta_{t o t, A H U}$ is efficiency of AHU unit. V and $\Delta \mathrm{p}$ are outputs based on the system design. $\eta_{t o t, A H U}$ is the matter of the technology efficiency and manufacturer selection. $\eta_{t o t, A H U}$ of AHU unit, acc. eq. (9). Efficiency $\eta_{t o t, A H U}$ is combination of more distinguished efficiencies:

$$
\eta_{\text {tot,AHU }}=\eta_{\text {drive }} \cdot \eta_{V F D} \cdot \eta_{F A N} \cdot \eta_{B E L T}
$$

Where $\eta_{\text {drive }}$ is electric motor efficiency $\left(88,7 \%\right.$ - EFF2 type), $\eta_{V F D}$ efficiency of variable speed drive $(98 \%), \eta_{F A N}$ is fan efficiency $(75,6 \%) \eta_{B E L T}$ is belt efficiency (in this case is 0 as for direct drive fan).

As already mentioned, control elements options gives the designer another dimension for the design and evaluation. In prepared computational model, damper locations in duct system hasn't been changed and stayed the same as they were designed in real building design. Only two parameters will be changed in the computation models:

- Damper regulator types between a), b) or c) according Fig.3.

- Whether to use or not the "hydraulically joined containers" principle for DCV minimizing air flow volume control, described in and around Fig.4.

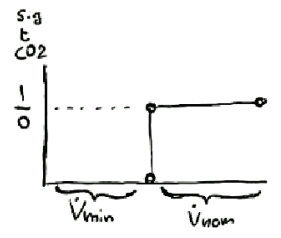

a)

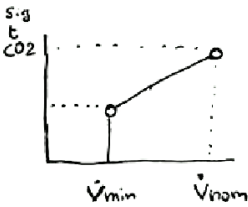

b)

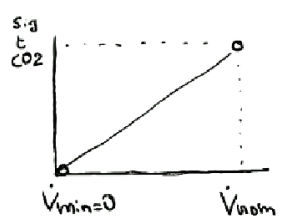

c)

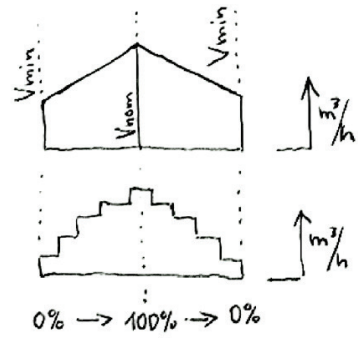

d)

Fig. 3. Regulation elements profiles: a) on/off regulator, b) and c): proportional regulators; d) loading profiles of zones.

Regulation elements profiles are described by linear dependence (less often by nonlinear description) as of a), b), c) in Fig. 3, a) on/off regulator, most simpler, knows only 2 positions; b) and c) are type of same proportional regulator, difference between them is that b) minimum value does not start in 0 but in some minimum value - operation in "off" position allows to pass minimum air volume through regulator. d) shows possible loading/unloading profiles of zone from minimum to maximum and backwards while 
unloading: upper is with b) and c) regulators, lower with a) regulator type, which is less accurate.

\section{The problematics of air distribution and control strategies}

After definition of the operating air flow demand is complete, specification of the regulation elements with their drives comes to place and without sophisticated data management it may be difficult to evaluate wide options in the design itself. Systems based on lowest installation costs demand may have lack of necessary regulation dampers for efficient operation. Case is described on Fig.4. Ventilation system consisting of main shaft duct route directs from fan in AHU F to specific floors with zones with air flow demands. Main open space zones defined as M ("mother zone") are biggest zones with demand for air. To $\mathrm{M}$ are connected other smaller zones such small offices D zones ("daughters"), utility rooms and meeting rooms R1. Let's say that R1 is not straight connected to the M and can have different occupants that are in other spaces (guests). In state Fig.4 a) is first operating schedule with demand of 138 air flow units, based on specific daughter zone needs and R1.

The state b) from Fig.4 shows different air demands, let's say, occupants from $M$ and other zones moved accordingly the new air demands and in R1 arrived few more guests. Is system able to bring +30 more air flow units to the floor and redistribute the air due to different local needs? The answer depends on set of regulation elements, in this example main dumper B and possible regulation places for dampers (V1,V2,V3,V4,V2.1). In the case, there would be only manual damper or CAV regulator on $\mathrm{B}$ position, there would not be possibility to flow more air into floor without an impact to whole building. If $\mathrm{B}$ would be VAV controller (in case other floors would have the same type), fan could supply 30 more air flow units to the floor but without the required effect - give the right amount of air to the right spaces - especially for new arrivals in R1 it wouldn't be possible. In the case, where total amount per floor would not be changed, but floor demand does as c) in Fig.5, the troubles would not bring possible manual damper in B but absence of regulation elements on $\mathrm{V}$ positions.

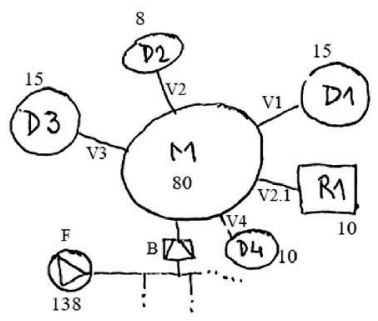

a)

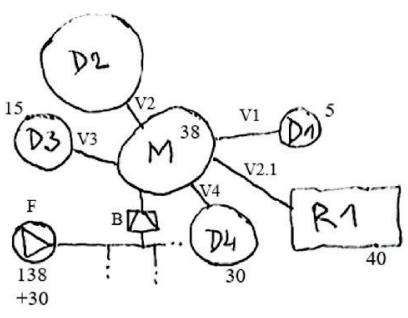

b)

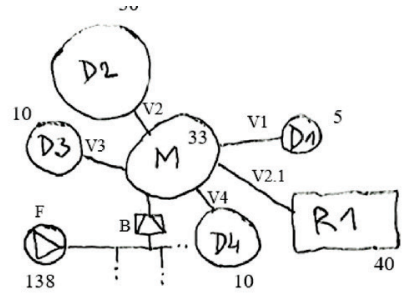

c)

Fig. 4. Description of duct system as hydraulically joined containers by designing right regulation elements. This gives the possibility to "detach" unnecessary air from specific zones for saving it.

Either the b) or c) case, is not possible to supply the right amount to the right places and carry off unnecessary air from zones where is wasteful. Most of systems today is not able to trespass from operation a) to b) without decreasing the required flow in $\mathrm{M}$ room from 80 to 38 and is able only to pump even more air (42 unit in this case) to the floor to fit the needs of daughter rooms. DCV approach leads us to necessity of maximum utilization of the air, where occupants will pass from mother room to the daughter rooms and same ratio of air will be added to daughter rooms and furthermore reduced from the mother room as well. This may has similar idea as hydraulically joined containers. 

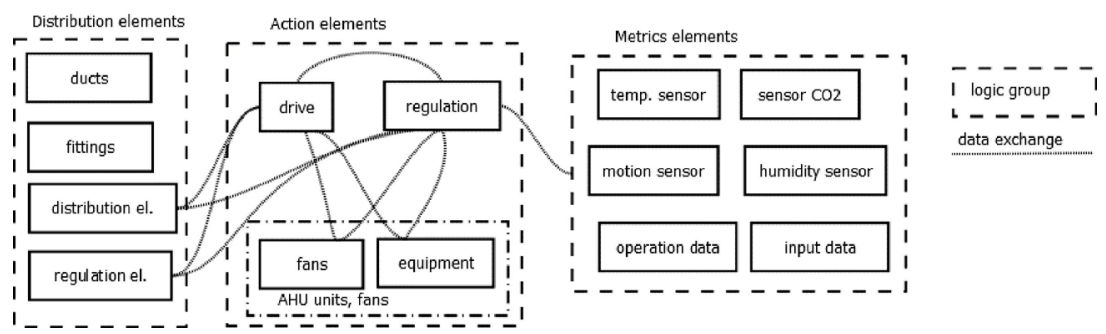

Fig. 5. Main elements of ventilation system grouped by their functionalities.

Not only because of possible issues described above, for creation of the computational model is necessary to decompose a whole system into the subsystems and their elements. By the elements division according the Fig.5 together with the definition of operating air flow volumes, control algorithm will be created. This has to consider the possible control options, which means, if fan is required to supply air to specific places, it needs already been determined, how many regulating points the air passes through till its final destination and also it needs to be determined how much each regulating element shall be opened. As result the algorithm made in design will send to fan exact data for control if implemented in operation. Based on this logic the exact regulation element profile as well as each room loading/unloading profile has to be determined.

Developing tool for design \& assessment will allow to import data from BIM parametric models and allows designer made its estimations on low costs on the basis design-analyse-redesign process in the acceptable time. Explicit definition of system elements and their impact on the total air flow distribution flexibility will be then in the results very clear.

\subsection{Next steps in research and validation of the models and discussion}

Much has already been written about the benefits and possibilities of DCV systems. These systems works properly if they obtain proper data for their control. Data are acquired by measurement the conditions in the room for is used for calculating the amount of energy actually required and for control the distribution routes for efficient air distribution.

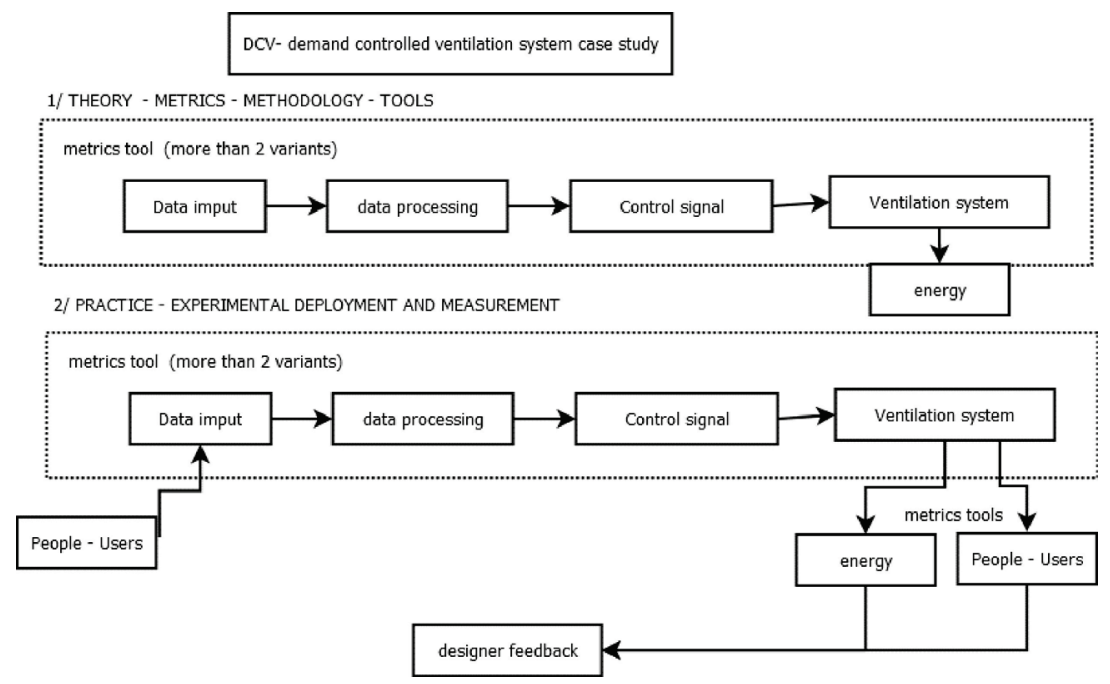

Fig. 6. Conceptual description of research topic steps. 
As stated in $[2,3]$, there are besides $\mathrm{CO} 2$ other measuring technologies which are experimentally tested, according [4, 5] were tested even their combinations for their complementing, however, each technology has its own restrictions. Today's most used CO2 sensors occupancy estimation is relatively exact but may interfere with long responsive time and air circulation patterns must be known.

The more developed metrics technology for obtaining exact and actual input data for system control, the higher chance to design and minimize air flow thus energy consumption as possible. Therefore the exact metric strategies for exact demand definition are nowadays developing and testing [5 - 9] and new are developing.

Further steps in the metrics technology research is to prepare possibilities to develop and test sophisticated metrics strategy based on an image-based processing, where continual occupants position monitoring and their movements can be achieved as stated in $[7,10]$ obtain exact values of occupancy rates within zones hand in hand with control logic defined in design model. As seen on Fig.6, computational model designed in developing tool is assumed later to be evaluated on site by implementation new metrics strategy to real control system and compare energy consumption differences with previous state and with computational model.

\section{References}

1. K. Ahmed, J. Kurnitski, P. Sormunen, Energy Build. 109, 115-126 (2015)

2. E. Naghiyev, M. Gillott, R. Wilson, Energy Build. 69, 507-514 (2014)

3. T. Labeodan, W. Zeiler, G. Boxem, Y. Zhao, Energy Build. 93, 303-314 (2015)

4. B. Dong, Energy Build. 42, 1038-1046 (2010)

5. H.B. Gunay, A.F. Fuller, W. O'Brien, W. Beausoleil-Morrison, I. Detecting occupants' presence in office spaces: A case study. eSim 2016 (2016)

6. J. Yang, M. Santamouris, S.E. Lee, C. Deb, Energy Build. 123, 192-204 (2016)

7. Y. Benezeth, H. Laurent, B. Emile, C. Rosenberger, Energy Build. 43, 305-314 (2011)

8. Resources, D., Features, D. \& Applications, F. People Counting for Demand Controlled Ventilation Using 3D Time-of-Flight (ToF) Reference Design. 1-58 (2016)

9. T. Kwevugbe, N. Brown, V. Pakka, D. Fan, Int. Conf. Enhanc. Build. Oper. (2013)

10. H.C. Shih, Energy Build. 77, 270-280 (2014) 
